\title{
Analytical method by liquid chromatography to assay piperine associated in nanoemulsions
}

\author{
Mariana H. Motta ${ }^{\mathrm{a}}$, Aline C. Schneider ${ }^{\mathrm{a}}$,Cristiane F. Codevilla ${ }^{\mathrm{b}}$, Cristiano R. Menezes ${ }^{\mathrm{b}}$, Cristiane de B. da \\ Silva ${ }^{*}, \mathrm{a}$ \\ ${ }^{a}$ Programa de Pós-Graduação em Ciências Farmacêuticas, Universidade Federal de Santa Maria, Av. Roraima, 1000, Santa \\ Maria, RS, 97105-900, Brazil \\ ${ }^{b}$ Programa de Pós-Graduação em Ciência e Tecnologia dos Alimentos, Universidade Federal de Santa Maria, Av. Roraima, \\ 1000, Santa Maria, RS, 97105-900, Brazil
}

\section{*Corresponding author: csbona@smail.ufsm.br}

This work aimed to develop and validate a simple, fast and low cost analytical method for the quantification of the bioactive piperine in nanoemulsions by high performance liquid chromatography with UV detection. Nanoemulsions were prepared by spontaneous emulsification and their physicochemical properties were evaluated. Considering the chromatographic conditions, the mobile phase was composed by methanol:water $(70: 30, \mathrm{v} / \mathrm{v})$, Gemini ${ }^{\circledR} \mathrm{C} 18$ column and UV detection at $343 \mathrm{~nm}$. The method was linear in the concentration range of $5-50 \mu \mathrm{g} \mathrm{mL}^{-1}(\mathrm{r}=0.9999)$, specific, precise (repeatability of RSD $0.38 \%$ and intermediate precision of RSD $1.11 \%$ ), accurate $(101.3 \%)$ and robust. Nanoemulsions showed nanometric droplet size, polidispersity index below 0.11 and negative zeta potential. The piperine content in the samples was $0.99 \pm 0.01 \mathrm{mg} \mathrm{mL}^{-1}$. Regarding these features, the analytical conditions proposed in this work were adequate and effective to determine the piperine content in nanoemulsions.

Keywords: Nanocarrier; Piper nigrum; Validation.

\section{Introduction}

The genus Piper belongs to the family Piperaceae. It has about 2000 species and it is found in tropical and subtropical regions. It is being used because of its diverse pharmacological properties, which includes anticancer, immunomodulatory, antioxidant and antiinflammatory properties (1). Piper nigrum L. is the best-known species, popularly known in Brazil as black pepper (2-4). Among the different types of peppers in the kingdom, black pepper is the more commercialized type being also used in cooking, medicinal preparations and esthetic products $(5,6)$.

The piperine (1-piperoyl-piperidine Figure 1) was the first isolated amide from the $P$. nigrum species carried out by a Danish chemist, Hans Christian Orstedt in 1820 (2,7). Piperine is the main constituent alkaloid and the main secondary metabolite of this species. It is responsible for the spicy taste and it is present in the concentration of $50-90 \mathrm{~g} \mathrm{~kg}^{-1}$ (8). It is characterized by being a yellowish crystalline substance with a melting point between 128-130 ${ }^{\circ} \mathrm{C}$ (9). Because of its insolubility in water, piperine acts as a weak base. In addition, it presents light instability being highly sensitive to light, which is an important characteristic (2).
In order to circumvent the therapeutic substances inconvenience, several systems or technological products have been developed. Nanoemulsions are colloidal dispersions characterized by a system consisting of oil droplets stabilized by surfactants. These nanostructured systems have a particle diameter smaller than $1 \mu \mathrm{m}$ and confer advantages, such as targeting the active substance at the specific site of action increasing the therapeutic effect and/or decreasing adverse effects (10-13) and promoting controlled release (14). Additionally, nanostructures can confer increased chemical stability to the associated active substances; for example, they protect them from light (15-17).

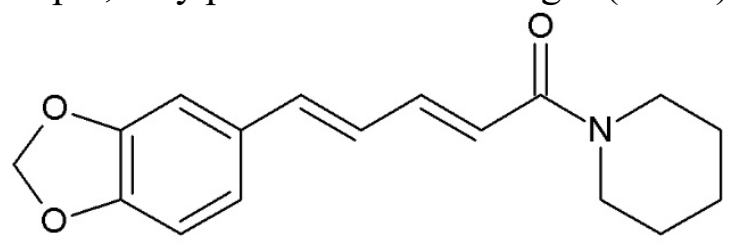

Figure 1. Piperine chemical structure.

One the most important parameters for the characterization of nanostructures is the content determination of the active substance present in these systems. Some methodologies by high performance liquid chromatography (HPLC) have been reported in the literature for the quantification of piperine. Moorthi et al. (2013) 
(18) developed a HPLC method to quantify piperine and curcumine in Eudragit ${ }^{\circledR}$ E100 nanoparticles. Another HPLC

method was developed by De Mey et al. (2014) (19) to determine piperine, piperidine and $\mathrm{N}$ nitrosopiperidine in spices such as black and white pepper, paprika, chili pepper, allspice and nutmeg. Gowda et al. (2014) (20) validated a highperformance liquid chromatography-electron spray ionization mass spectrometry method to quantify guggulsterones, piperine and gallic acid in commercial samples of Triphala guggulu. However, no HPLC methods are reported to quantify this isolated bioactive compound in the nanostructures present in this work.

Considering this, this work aimed to develop and validate an analytical method by HPLC to quantify the piperine in nanoemulsions. The analytical conditions proposed in this work in terms of sample preparation and mobile phase were selected in order to obtain a simple and robust method with low cost. Moreover, the developed nanoemulsions represent an important nanocarrier system to promote greater bioactive stability and constitute a novel medicine or cosmetic, mainly because of the antioxidant $(21,22)$ and antitumor $(23)$ piperine properties.

\section{Experimental}

\section{Material}

Piperine (95.98\%, w/w) was obtained
from GAMA (São $\quad$ Paulo,
Chromatographic grade methanol was purchased from Tedia (São Paulo, Brazil); Ultrapure water was purified by the MegaPurity Mega RO apparatus (Rio de Janeiro, Brazil). For the preparation of the nanoemulsions it was used sorbitan monooleate $\left(\operatorname{Span}^{\circledR} 80\right)$ obtained from Sigma-Aldrich (Sao Paulo, Brazil); Medium chain triglycerides (MCT) purchased from Delaware (Porto Alegre, Brazil); polysorbate 80 (Tween ${ }^{\circledR}$ 80) from Vetec (Rio de Janeiro, Brazil) and acetone from Química Moderna (São Paulo, Brazil).

\section{Nanoemulsions preparation}

Nanoemulsions containing piperine (P-NE) were prepared by the spontaneous emulsification method (24). The constituents of the organic phase were: the oil (MCT - $0.4 \mathrm{~g}$ ), the low HLB surfactant $\left(\operatorname{Span}^{\circledR} 80-0.1925 \mathrm{~g}\right)$, the bioactive $(0.026 \mathrm{~g})$ and the solvent miscible in water (acetone $-67 \mathrm{~mL}$ ). The phase was stirred for the components dissolution for 30 minutes. This phase was then injected into an aqueous phase, consisting of a high HLB surfactant (Tween ${ }^{\circledR} 80$ $0.1925 \mathrm{~g})$ and ultrapure water $(134 \mathrm{~mL})$ under constant magnetic stirring maintained for 10 minutes after the addition of the phases. After, the formulation was taken to the rotary evaporator at $40{ }^{\circ} \mathrm{C}$ to remove the organic solvent and adjust the final volume $(25 \mathrm{~mL})$ and the piperine concentration $\left(1.0 \mathrm{mg} \mathrm{mL} \mathrm{m}^{-1}\right)$. For comparison purposes, blank nanoemulsions (without piperine) were also prepared (NE). All formulations were prepared in triplicate and stored in amber glass vials, kept under light and environment protection.

\section{Analytical method validation}

For the analysis, an Agilent liquid chromatograph 1260 Infinity (California, USA), consisting of a 1260 quart pump VL, detector 1260 VWD VL, control center and ALS automatic injector was used. Data were analyzed with the OpenLab program, version A.01.05. For the stationary phase, a Gemini ${ }^{\circledR}$ Phenomenex C-18 column $(150 \times 4.6 \mathrm{~mm}, 5 \mu \mathrm{m}$ along with a precolumn Phenomenex ${ }^{\circledR}$ C-18 $(4.0 \times 3.0 \mathrm{~mm}, 5 \mu \mathrm{m})$ was employed. The mobile phase was composed of methanol:water $(70: 30, \mathrm{v} / \mathrm{v})$. The equipment was operated at environment temperature using an isocratic flow of $1.0 \mathrm{~mL} \mathrm{~min}^{-1}$ and $\mathrm{UV}$ detection at $343 \mathrm{~nm}$.

\section{Sample preparation}

A $400 \mu \mathrm{L}$ aliquot of the P-NE was diluted in a $20 \mathrm{~mL}$ volumetric flask with methanol and shaken at $1,100 \mathrm{rpm}$ for 30 minutes. In sequence, the flask was calibrated to obtain a piperine concentration of $20 \mu \mathrm{g} \mathrm{mL} \mathrm{m}^{-1}$. For analysis in the chromatograph, the samples were previously filtered on regenerated cellulose membrane $(0.45$ $\mu \mathrm{m}$, Sartorius Stedim Biotech, Goettingen, Germany) and performed in triplicate.

\section{Reference solution preparation}


The stock solution was prepared weighing exactly $26 \mathrm{mg}$ of piperine, transferred to a $25 \mathrm{~mL}$ volumetric flask, diluted in methanol to obtain a concentration of $1.0 \mathrm{mg} \mathrm{mL}^{-1}$. After, a $400 \mu \mathrm{L}$ aliquot was diluted in methanol $(20 \mathrm{~mL})$ in order to obtain the standard solution of $20 \mu \mathrm{g} \mathrm{mL}^{-1}$.

The analyzed parameters in the validation of analytical method were: specificity, linearity, precision (repeatability and intermediate precision), accuracy and robustness $(25,26)$.

Specificity

To evaluate the method specificity, nanoemulsions were used without the presence of the bioactive; however, they contained other excipients. For this, the samples were submitted to the same process of the samples containing the bioactive, injected into the chromatograph and analyzed for possible interference of the formulation constituents. In addition, to determine the piperine chromatographic peak purity, another chromatograph was used (Shimadzu LC-20A, Kyoto, Japan) equipped with LC-20AT pump, SPD-M20A PDA detector and CBM-20A controller system. The same analytical conditions previously described were used.

\section{Linearity and detection and quantification coefficients}

Analytical curves were prepared from the piperine stock solution. Aliquots of this solution were diluted in methanol, in order to obtain 5,10 , 20, 30, 40 and $50 \mu \mathrm{g} \mathrm{mL} \mathrm{m}^{-1}$ piperine solutions. Three independent analytical curves were constructed and the linearity was obtained by linear regression using the least squares method and analyzed by analysis of variance (ANOVA).

From the analytical curve, the limits of detection and quantification were calculated following equations 1 and 2 :

$$
\begin{aligned}
& \mathrm{LD}=3.3 \times \mathrm{SD} / \mathrm{S}(1) \\
& \mathrm{LQ}=10 \times \mathrm{SD} / \mathrm{S}(2)
\end{aligned}
$$

Where SD $=$ standard deviation of the intercept and $\mathrm{S}=$ slope of the analytical curve

\section{Precision}

Precision was obtained from the analysis of repeatability and intermediate precision. The repeatability was evaluated by analyzing six distinct samples of $20 \mu \mathrm{g} \mathrm{mL}^{-1}$ performed on the same day and under the same experimental conditions. For the intermediate precision, three samples of the same concentration $\left(20 \mu \mathrm{g} \mathrm{mL}^{-1}\right)$ were analyzed on three different days. The results were evaluated and expressed in relation to the relative standard deviation (RSD).

\section{Accuracy}

Accuracy was assessed by the recovery test, expressed by the quantity of piperine recovered from the samples $(n=3)$. For the test, three samples containing $200 \mu \mathrm{L}$ of the nanoemulsions were extracted in methanol, in order to obtain $10 \mu \mathrm{g} \mathrm{mL}^{-1}$ of piperine solution. To these samples were added known concentrations of the stock solution to obtain concentrations of 16,20 and $24 \mu \mathrm{g} \mathrm{mL}^{-1}$ of bioactive, corresponding to 80,100 and $120 \%$ of the usual analysis concentration $\left(20 \mu \mathrm{g} \mathrm{mL}^{-1}\right)$.

\section{Robustness}

The method robustness was evaluated using the following parameters: wavelength (341 and $345 \mathrm{~nm}$ ), proportion of the mobile phase (65:35 and 75:25, methanol:water) and exchange Equipment (Schimadzu LC-20A, Kyoto, Japan).

\section{Nanoemulsions physicochemical characterization}

After preparation, the nanoemulsions were evaluated in relation to their physicochemical properties. The analyses were made in triplicate.

The $\mathrm{pH}$ determination was performed in a potentiometer (Seven Easy, Metler Toledo, Brazil) previously calibrated with buffer solutions $\mathrm{pH} 4.0$ and 7.0 directly in the samples.

The samples were evaluated in relation to the granulometric profile by laser diffraction (Mastersizer $^{\circledR}$ 3000E, Malvern Instruments). Analyses were performed in water (refractive index 1.33) and agitated at $1,750 \mathrm{rpm}$. Results were analyzed according to Mie Theory of light scattering considering the refractive index of MCT (1.46). 
Mean droplet diameter and polydispersity index of the nanoemulsions were determined by correlation spectroscopy of photons (Zetasizer ${ }^{\circledR}$ Nanoseries, Malvern Instruments) after the samples dispersion in previously filtered ultrapure water $(1: 500, \mathrm{v} / \mathrm{v})$. The zeta potential was evaluated by electrophoretic mobility in the same equipment. For the analyses, the samples were dispersed in $10 \mathrm{mM} \mathrm{NaCl}$ solution $(1: 500, \mathrm{v} / \mathrm{v})$.

The content of piperine in the nanoemulsions was determined by HPLC using the validated methodology. In addition, the encapsulation efficiency was determined by ultrafiltration-centrifugation technique $\left(\right.$ Amicon $^{\circledR}$ 10,000 MW, Millipore) at 2,200 xG for 30 minutes. The non-associated piperine content with the nanocarrier was calculated by the difference between the total concentration of piperine and the concentration found in the ultrafiltrate.

\section{Results and discussion}

\section{Analytical method validation}

In order to develop an analytical methodology for the quantification of drugs incorporated in nanocarriers, it is necessary to ensure that such methodology is able to separate and quantify the drug from the system to which it is associated. Furthermore, the excipients of the formulation or the possible degradation products should also be considered. For this, HPLC is one of the most studied methodologies for the analysis of nanostructured drugs $(27,28)$ with excellent sensitivity and reproducibility.

Initially, for the selection of the ideal mobile phase, some tests were performed aiming to find a simple and low cost eluent system. There are some reports in the literature, but none exclusively about piperine (18-20). The choice for methanol is due to the low cost in comparison with other solvents, thus $100 \%$ methanol and methanol:water in different proportions (95:5, $80: 20$ and $70: 30, \mathrm{v} / \mathrm{v})$ were tested. The use of $100 \%$ methanol and $0.5 \mathrm{~mL} \cdot \mathrm{min}^{-1}$ flow rate resulted in a low retention time, very close to the dead volume (3.92 min). Similar result was found for the 95:5 ratio. The proportions of 80:20 and
70:30 provided similar results, with a retention time of 6.29 and $6.27 \mathrm{~min}$, respectively. Besides, theoretical plates with suitable values $(4,016$ and 3,303 ) were found as well. However, the resolution and asymmetry were better for the $70: 30$ ratio (4.15 and 0.81 , respectively).

The chosen mobile phase was composed of methanol:water $(70: 30, \mathrm{v} / \mathrm{v})$, which presented to be a simple eluent system, in addition to providing a lower amount of organic solvent. This mobile phase is more economical than the used by De Mey et al. (2014) (19), which employed 100\% methanol as the mobile phase. In another HPLC method (Moorthi et al. 2013) (18), the mobile phase was composed of an ortho phosphoric acid aqueous solution and acetonitrile, with a higher flow rate $\left(1.2 \mathrm{~mL} \mathrm{~min}^{-1}\right)$, which implies a more elaborate mobile phase and a higher associated cost. Therefore, the chosen mobile phase showed to be suitable for the analysis presenting a retention time around 6.3 minutes, satisfactory

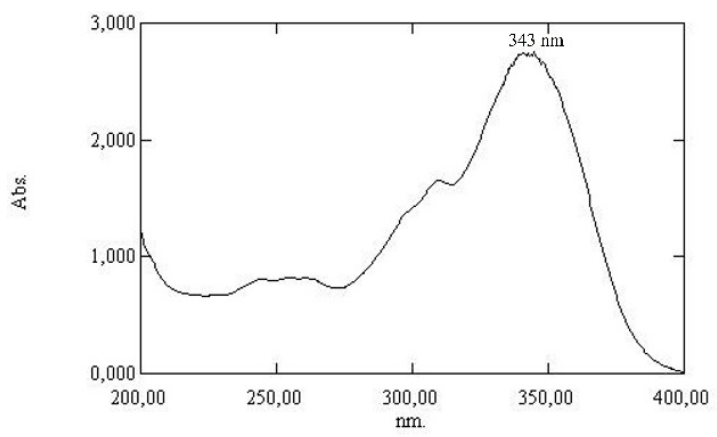

asymmetry and theoretical plates. Moreover, the UV scanning of piperine (Figure 2) was performed and the spectra shows $343 \mathrm{~nm}$ to be the wavelength of maximum absorbance of the bioactive.

Figure 2. UV scanning of piperine (methanolic solution at $10.0 \mu \mathrm{g}$ $\mathrm{mL}^{-1}$ - Shimadzu Corporation UV1800 Spectrophotometer).

Regarding specificity, the method proved to be specific for piperine analysis, showing that none of the formulation excipients were eluted in the same retention time as the piperine peak. In Figure 3, the overlapping of piperine solution (P$\mathrm{S})$ and the formulation with and without piperine (P-NE and NE) ratifies the absence of other peaks at the same retention time as the bioactive. 
Drug Anal Res, 2018; 02, n.1, 1-7

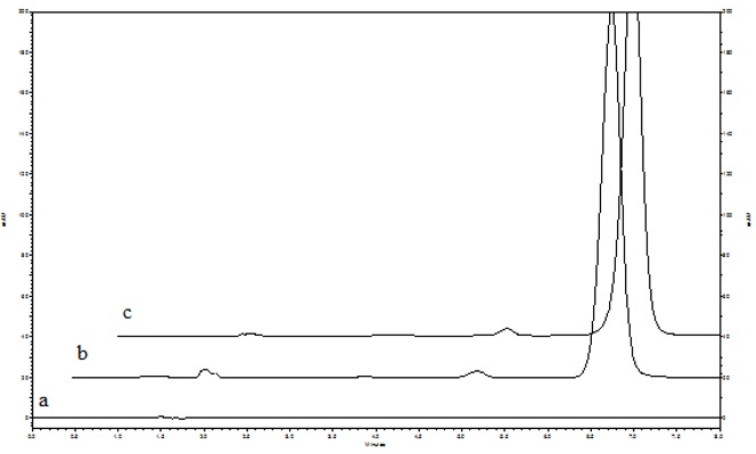

Figure 3. Chromatograms obtained by HPLC: a) nanoemulsion without bioactive (NE); b) methanolic solution of piperine at 20.0 $\mu \mathrm{g} \mathrm{mL}{ }^{-1}$, and c) piperine-loaded nanoemulsion (P-NE - 20.0 $\mu \mathrm{g}$ $\left.\mathrm{mL}^{-1}\right)$.

In relation to linearity, the curves were submitted to analysis of variance (ANOVA) having an adequate correlation coefficient $(\mathrm{r}=0.9999$; $\mathrm{y}$ $=258166 \mathrm{x}-103392)$, significant linear regression $($ Fcalculated $=29462.98>$ Ftabulated $=4.75)$ and presented no linearity deviation (Fcalculated $=$ $2.66<$ Ftabulated $=3.26$ ), demonstrating that the method is linear in the concentration range of 5 to $50 \mu \mathrm{g} \mathrm{mL}^{-1}$. The values of LQ and LD were also calculated and corresponded to $1.26 \mu \mathrm{g} \mathrm{mL}^{-1}$ and $0.41 \mu \mathrm{g} \mathrm{mL}^{-1}$, respectively.

The results of the precision (repeatability and intermediate precision) are described in Table 1. The relative standard deviation (RSD) values found were $0.38 \%$ and $1.11 \%$ for repeatability and intermediate precision, respectively, demonstrating that the method is precise within the analyzed concentration range. The accuracy was evaluated by the recovery test and, the average percentage found was $101.35 \pm 0.80 \%$, evidencing that the method is accurate (Table 2).

Table 1. Results found in the precision parameter of the analytical method by HPLC (repeatability and intermediate precision) for the analysis of piperine in nanoemulsions.

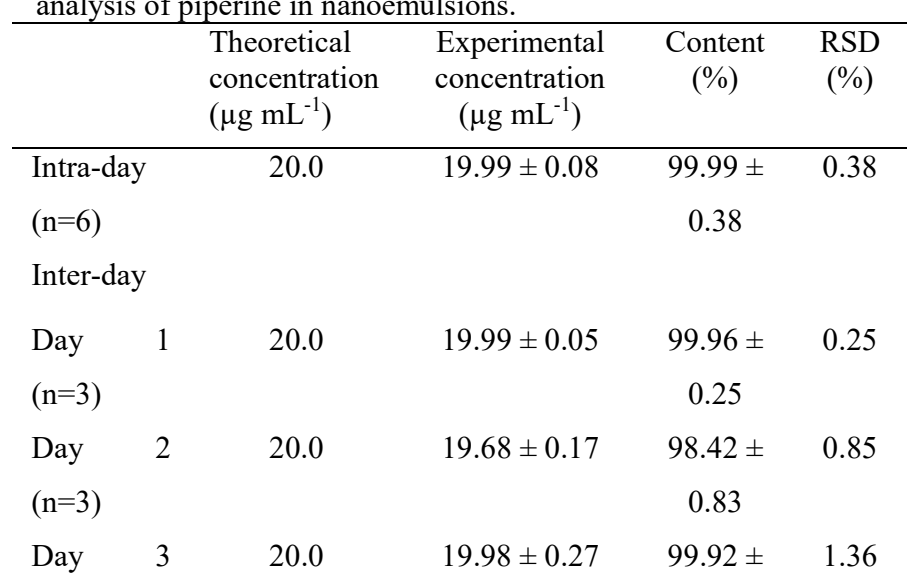

\begin{tabular}{|c|c|c|c|}
\hline$(n=3)$ & & & 1.36 \\
\hline Average & 20.0 & $19.89 \pm 0.22$ & $99.43 \pm$ \\
\hline$(n=9)$ & & & 1.11 \\
\hline
\end{tabular}

Table 2. Results found in the accuracy of the analytical method for the analysis of piperine in nanoemulsions by HPLC $(n=3)$.

Sampl Concentration $(\mu \mathrm{g}$ Recover RS Mean

\begin{tabular}{|c|c|c|c|c|c|}
\hline \multirow{2}{*}{$\begin{array}{l}\mathrm{e} \\
10 \mu \mathrm{g}\end{array}$} & \multicolumn{2}{|c|}{$\left.\mathrm{mL}^{-1}\right)$} & \multirow{3}{*}{$\begin{array}{c}\mathrm{y} \\
(\%)\end{array}$} & \multirow{3}{*}{$\begin{array}{c}\mathrm{D} \\
(\%)\end{array}$} & \multirow{3}{*}{$\begin{array}{c}\text { recovery } \\
(\%)\end{array}$} \\
\hline & Added & Recove & & & \\
\hline $\mathrm{mL}^{-1}$ & & red & & & \\
\hline & \multirow[t]{2}{*}{6.00} & $6.03 \pm$ & 100.59 & & \\
\hline & & 0.10 & \pm 1.68 & & \\
\hline & \multirow[t]{2}{*}{10.00} & $10.22 \pm$ & 102.19 & 0.7 & $101.35 \pm$ \\
\hline & & 0.14 & \pm 1.39 & 9 & 0.80 \\
\hline & \multirow[t]{2}{*}{14.00} & $14.18 \pm$ & 101.27 & & \\
\hline & & 0.06 & \pm 0.40 & & \\
\hline
\end{tabular}

The results obtained for the analytical method robustness are showed in Table 3. The small variations in the wavelength, proportion of the mobile phase and equipment change did not affect the chromatographic method developed, indicating the robustness of the same.

Table 3. Analysis of the analytical method robustness by HPLC for the quantification of piperine in nanoemulsions.

\begin{tabular}{|c|c|c|c|c|c|}
\hline Conditions & $\begin{array}{c}\text { Theoretical } \\
\text { plates }\end{array}$ & $\begin{array}{c}\text { Tail } \\
\text { factor }\end{array}$ & $\begin{array}{c}\text { Retention } \\
\text { time }\end{array}$ & $\begin{array}{c}\text { Piperine } \\
\text { content } \\
(\%)\end{array}$ & $\begin{array}{l}\text { RSD } \\
(\%)\end{array}$ \\
\hline $\begin{array}{l}\text { Recommended } \\
\text { conditions } \\
\text { Mobile phase } \\
(v / v)\end{array}$ & 3373.7 & 0.33 & 6.01 & $\begin{array}{l}100.01 \\
\pm 0.71\end{array}$ & 0.71 \\
\hline $65: 35$ & 3824 & 0.82 & 10.02 & $\begin{array}{c}99.81 \pm \\
0.28\end{array}$ & 0.28 \\
\hline $75: 25$ & 3425 & 0.02 & 4.40 & $\begin{array}{l}100.02 \\
\pm 0.98\end{array}$ & 0.98 \\
\hline$\lambda(\mathrm{nm})$ & & & & & \\
\hline 341 & 3390.3 & 0.33 & 6.00 & $\begin{array}{c}99.57 \pm \\
0.64\end{array}$ & 0.65 \\
\hline 345 & 3394.3 & 0.33 & 5.99 & $\begin{array}{c}99.46 \pm \\
0.33\end{array}$ & 0.34 \\
\hline Equipment & & & & & \\
\hline $\begin{array}{l}\text { Shimadzu } \\
\text { HPLC }\end{array}$ & 4978.9 & 1.17 & 5.80 & $\begin{array}{c}99.41 \pm \\
1.08\end{array}$ & 1.08 \\
\hline
\end{tabular}

Nanoemulsions physicochemical characterization 
After preparation, the formulations were macroscopically evaluated, presenting a milky and opalescent aspect, bluish-like appearance (Tyndall effect), known as the Brownian motion of colloidal systems.

Piperine-loaded nanoemulsions (P-NE) and blank formulations (NE) presented, respectively, nanometric droplet size (182 \pm 2 and $176 \pm 2 \mathrm{~nm}$ ) and polydispersity index below 0.15 $(0.09 \pm 0.04$ and $0.10 \pm 0.04)$ showing the adequate systemic homogeneity. The results of the droplet size by laser diffraction added to the previous one demonstrated a nanometric distribution, with a unimodal peak, without the presence of micrometric particles. The nanoemulsions presented Span values close to unity $(0.628)$ and $\mathrm{D}[4,3]$ of $0.471 \mu \mathrm{m}$, confirming the homogeneity of the system, without the presence of microparticles (Figure 4). It can also be observed that the addition of the bioactive in the formulations did not influence the size ( $p>0.05$ ). Savian et al. (2015) (17) found similar results using the same preparation method to prepare dithranol-loaded nanoemulsions.

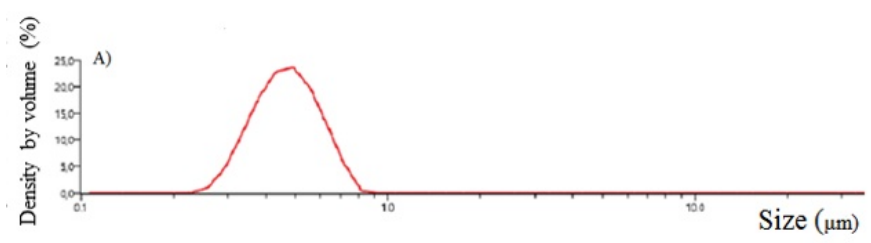

Figure 4. Droplet size distribution of P-NE $\left(1.0 \mathrm{mg} \mathrm{mL}^{-1}\right)$ analyzed by laser diffraction.

Regarding the $\mathrm{pH}$, the formulations presented acidic values $(6.38 \pm 0.09$ and $6.27 \pm$ 0.07 for P-NE and NE, respectively). Slightly higher $\mathrm{pH}$ values were found when the bioactive was added to the formulations, probably because of the piperine physicochemical properties.

In relation to zeta potential, the samples presented negative values $(-6.3 \pm 0.4$ and $-8.5 \pm$ $0.4 \mathrm{mV}$ for P-NE and NE, respectively), which was caused by the adsorption of polyssorbate 80 molecules to the oil-water interface. The low zeta potential values, in modulus, are typical for polyssorbate 80 , a nonionic surfactant, and the presence of impurities, such as fatty acids, produces negative charge oil droplets $(29,30)$.

Regarding the bioactive content, the nanocarriers presented values close to the theoretical value $\left(0.99 \pm 0.01 \mathrm{mg} \mathrm{mL} \mathrm{mL}^{-1}\right)$ and encapsulation efficiency of $98.5 \pm 0.1 \%$. It is important to mention that our results are satisfactory and showed the high piperine capacity of being associated with the nanoemulsions proposed in this work, in comparison to other works reported in the literature. Pachauri et al. (2015) (31) developed PEG-PLGA nanoparticles containing piperine, which presented encapsulation efficiency around $38 \%$; and in other two studies, values of $78 \%$ and $94 \%$ were obtained by Boddupalli et al. (2013) (32) and Moorthi (2013) (18), respectively.

\section{Conclusions}

A fast, simple and efficient method by HPLC with UV detection was developed for the quantification of piperine in nanoemulsions. The proposed method proved to be specific, linear, precise, accurate and robust. The results demonstrated that the method can be a suitable technique to quantify piperine in nanoemulsion formulations and can be used in bulk form, encouraging its application for quality control. In addition, this work showed the possibility of the association of piperine with nanoemulsions presenting nanometric droplet size and efficiency association of about $98 \%$, which are considered satisfactory characteristics for this type of nanocarrier.

\section{Acknowledgments}

MHM and ACS are grateful to CAPES and PIBIT/CNPq/UFSM, respectively, for the scholarship. CBS thanks the financial support by $\mathrm{CNPq} /$ Brazil.

\section{Conflict of interest}

The authors declare no conflict of interest.

\section{References}

1. Meghawal M, Goswami TK; Phytother. Res. 2013, 27, 1121-1130.

2. Butt MS, Pasha I, Sultan MT, Randhawa MA, Saeed F, Ahmed W. Crit. Rev. Food Sci. Nutr. 2013, 53, 37-41.

3. Polovka M, Suhaj M. Food Rev. Int. 2010, 26, 138-161. 
4. Srinivasan K. Indian Food Ind. 2008, 27, 36-47.

5. de Souza EL, Stamford TLM, Lima EO, Trajano VN, Barbosa JMJr. Braz. Arch. Biol. Technol. 2005, 48, 549-558.

6. Srinivasan K. Food Rev. Int. 2005, 21, 167-188.

7. Ferreira WS, Franklin TN, Lopes ND, de Lima MEF. Rev. Virtual Quim. 2012, 4, 208-224.

8. Thiel A, Buskens C, Woehrle T, Etheve S, Schoenmakers A, Fehr M, Beilstein P. Food Chem. Toxicol. 2014, 66, 350-357.

9. McNamara FN, Randall A, Gunthorpe MJ. Br. J. Pharmacol. 2005, 144, 781-790.

10. Charcosset C, El-Harati A, Fessi H. J. Membr. Sci. 2005, 108, 115-120.

11. Couvreur P, Barrat G, Fattal E, Legrand P, Vauthier C. Crit. Rev. Ther. Drug Carrier Syst. 2002, 19, 99-134.

12. Rawat M, Singh D, Saraf S. Biol. Pharma. Bull. 2006, 29, 1790-1798.

13. Schaffazick SR, Freitas LL, Pohlmann AR, Guterres SS. Quim. Nova. 2003, 26, 726-737.

14. Mishra B, Bhavesh PB, Tiwari S. Nanomedicine. 2010, 6, 9-24.

15. Fontana MC, Coradini K, Guterres SS, Pohlmann AR, Beck RCR. J. Biomed. Nanotechnol. 2009, 5, 254-263.

16. Ourique AF, Pohlmann AR, Guterres SS, Beck RCR. Int. J. Pharma. 2008, 352, 1-4.

17. Savian AL, Rodrigues D, Weber J, Ribeiro RF, Motta MH, Schaffazick SR, Adams AIH, Andrade DF, Beck RCR, Silva CB. Mater. Sci. Eng. C. 2015, 46, 69-76.

18. Moorthi C, Krishnan K, Manavalan R, Kathiresan K. Asian Pac. J. Trop. Biomed. 2012, 2, 841-848.

19. De Mey E, De Maere H, Dewulf L, Paelinck H, Sajewicz M, Fraeye I, Kowalska T. Eur. Food Res. Technol. 2014, 238, 477-484.

20. Gowda DV, Mugulil G, Jadhav AN, Nagraja P, Sarathchandraprakash, Babu UV, Paramesh R, Deshpande RD. Indo Am. J. Pharm. Res. 2014, 4, 4042-4046.

21. Su L, Yin JJ, Charles D, Zhow K, Moore J, Yu L. Food Chem. 2007, 100, 990-997.
22. Kapoor IPS, Singh B, Singh G, DeHeluani CS, De-Lampasona MP, Catalan CAN. Journal of Agricultural and Food Chem. 2009, 57, 5358-5364.

23. Selvendiram K, Banu, SM, Sakthisekaram D. Clin. Chim. Acta. 2004, 350, 73-78.

24. Bouchemal K, Briançon S, Perrier E, Fessi H. Int. J. Pharm. 2004, 280, 241.

25. International Conference Harmonization (ICH), Validation of Analytical Procedures: Text and Methodology, Q2 (R1), 2005.

26. Kapoor IPS, Singh B, Singh G, DeHeluani CS, De-Lampasona MP, Catalan CAN. Journal of Agricultural and Food Chem. 2009, 57, 5358-5364.

27. Selvendiram K, Banu, SM, Sakthisekaram D. Clin. Chim. Acta. 2004, 350, 73-78.

28. Bouchemal K, Briançon S, Perrier E, Fessi H. Int. J. Pharm. 2004, 280, 241.

29. International Conference on Harmonization ( $\mathrm{ICH})$, Validation of Analytical Procedures: Text and Methodology, Q2 (R1), 2005.

30. Brazil. Agência Nacional de Vigilância Sanitária. 2017. Resolução RDC n ${ }^{\circ} 166$ de 27 de Julho de 2017. Dispõe sobre a validação de métodos analíticos e dá outras providências, Diário Oficial da União: Brasília.

31. Härter APG, Motta MH, Barros JG, Ribeiro RF, Adams AIH, Schaffazick SR, Silva CB. Quim. Nova. 2015, 37, 996-999

32. Lopes CE, Langoski G, Klein T, Ferrari PC, Farago PV. Braz. J. Pharm. Sci. 2017, 53, 1-9.

33. Salvia-Trujillo L, Sun Q, Um BH, Park Y, McClements DJ. J. Funct. Foods. 2015, 17, 293-304.

34. Cattani VB, Fiel LA, Jäger A, Jäger E, Colomé LM, Uchoa F, Stefani V, Costa TD, Guterres SS, Pohlmann AR. Eur $J$ Pharm Sci. 2010, 39, 116-124.

35. Pachauri M, Gupta ED, Ghosh PC. J Drug Deliv. Sci. Technol. 2015, 29, 269282.

36. Boddupalli BM, Masana P, Anisetti RN, Kallem SV, Madipoju B. Drug Inv. Today. 2013, 5, 212-215. 